\title{
SURGICAL IMPORTANCE OF CATERPILLAR (MOYNIHAN) HUMP OF RIGHT HEPATIC ARTERY
}

\author{
K. Sangameswaran ${ }^{* 1}$, M. Rohini devi ${ }^{2}$. \\ *1 Assistant Professor, Department of Anatomy, Coimbatore Medical College, Coimbatore, \\ Tamilnadu, India.
}

2 Associate Professor, Department of Anatomy, Coimbatore Medical College, Coimbatore, Tamilnadu, India.

\section{ABSTRACT}

Background: Ligation of cystic artery is a procedural prerequisite during any surgical procedure involving gallbladder. In some cases, right hepatic artery may come very close to gallbladder \& cystic duct in the form of "Caterpillar hump or Moynihan hump". If such a hump is present, the cystic artery inturn is very short. In this situation right hepatic artery is liable to be mistakenly identified as cystic artery and it will be ligated prior to Cholecystectomy. So, right functional lobe of liver goes for necrosis.

Materials and Methods: 60 adult specimens from cadavers were studied by using conventional dissection method in institute of anatomy, Madras Medical college, Chennai, Tamilnadu, India. While age and sex were not determined.

Results: Caterpillar hump (Moynihan hump) of right hepatic artery was present in 2 specimens (3.33 \%) in my study.

Conclusion: The responsibility for teaching the arterial variations to surgeons lies with the anatomists. So that the surgeons can able to identify this arterial variation during their cholecystectomy surgeries. If this caterpillar hump of right hepatic artery is present, the surgeons should locate the origin of cystic artery to avoid any unnecessary confusion between cystic artery and right hepatic artery for preventing unnecessary damage to the right hepatic artery.

KEY WORDS: Caterpillar hump, Moynihan hump, Right hepatic artery, Cystic artery, Cholecystectomy.

Address for Correspondence: Dr.K. Sangameswaran. M.S , Assistant professor, Department of Anatomy, Coimbatore Medical College, Coimbatore, Tamilnadu, India.

E-Mail: drsangames@gmail.com

\section{Access this Article online}

\begin{tabular}{|c|c|c|}
\hline \multirow{2}{*}{ 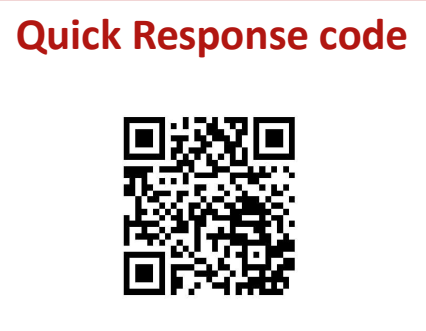 } & \multicolumn{2}{|c|}{$\begin{array}{l}\text { Web site: International Journal of Anatomy and Research } \\
\text { ISSN 2321-4287 } \\
\text { www.ijmhr.org/ijar.htm }\end{array}$} \\
\hline & $\begin{array}{l}\text { Received: } 04 \text { Feb } 2017 \\
\text { Peer Review: 05 Feb } 2017\end{array}$ & $\begin{array}{l}\text { Accepted: 13 Mar } 2017 \\
\text { Published (O): } 30 \text { Apr } 2017\end{array}$ \\
\hline & Revised: None & Published (P): 30 Apr 2017 \\
\hline
\end{tabular}

\section{INTRODUCTION}

A pear shaped gall bladder lies in a fossa on the undersurface of the liver. With a capacity of about $50 \mathrm{ml}$, it stores and concentrates the bile secreted by the liver. Liver and extrahepatic biliary apparatus are developed from the distal part of primitive foregut. The celiac trunk is an arterial trunk, arises as a ventral branch of abdominal aorta at the level of the junction of T12 and L1 vertebrae. Celiac trunk gives blood supply to the structures derived from the distal part of the foregut through its three branches such as left gastric artery, common hepatic artery and splenic artery.

The main artery supplying the liver and extrahepatic biliary apparatus is the common hepatic 
artery, which continues as proper hepatic artery after it gives off the gastroduodenal branch. The proper hepatic artery divides into right and left hepatic arteries for supplying the blood to the right and left functional lobes of the liver respectively .

Cystic artery gives blood supply to the gallbladder. Before approaching the gall bladder this artery enters into a triangular space below the liver as a branch of right hepatic artery. This space is called as "Hepato cystic triangle or Triangle of Calot ". Upper border of Calot's triangle is formed by the inferior surface of the liver, and the other two boundaries are the cystic duct ( laterally )and common hepatic duct (medially). Usually the cystic artery arises from the right hepatic artery when the latter crossing common hepatic duct posteriorly.

Aim: Nowadays gallstone has become as one of the commonest health problems in our society, and it is present in approximately $10 \%$ of the people over the age of 40 years, and more common in women [1] . Symptomatic gallstone is the most common indication for surgical removal of gallbladder (Cholecystectomy). The other indications for cholecystectomy are recurrent attacks of cholecystitis, Mirizzi's syndrome and malignancy of gallbladder [2].

In the initial stage of the cholecystectomy procedure, cystic artery is first ligated and divided after which the cystic duct and its junction with the common bile duct is defined [3]. Cystic artery arises from the right hepatic artery when the latter crossing common hepatic duct posteriorly. Arterial variations are common than ductal variations in Calot's triangle [4]. It is usually the right hepatic artery that is in danger during this surgery and must be located before ligating the cystic artery [5]. Because numerous variations in origin and branching pattern of right hepatic artery have been reported. In some cases tortuous right hepatic artery producing sinuosity, and it may come very close to the gallbladder and cystic duct in the form of "CATERPILLAR HUMP or MOYNIHAN'S HUMP" [6] . If such a hump is present, the cystic artery inturn is very short. In this situation right hepatic artery is either liable to be mistakenly identified as cystic artery or torn in attempts to ligate the cystic artery [7]. Injury to right hepatic artery leads to ischemic necrosis of right functional lobe of the liver [8] . So presence of caterpillar hump should be suspected when an unusually large cystic artery is viewed through the laparoscope [9] .

The responsibility for teaching the arterial variations to surgeons lies with the anatomists. So the surgeons can able to identify this arterial variation during their surgeries. Because of this, aim of my present study is to find out the incidence of caterpillar hump variation of right hepatic artery in cadavers, and I hope that will give useful information to the surgeons about this variation to avoid iatrogenic complications in their patients.

\section{MATERIALS AND METHODS}

60 adult specimens from cadavers were studied by using conventional dissection method as given in Cunninghams manual of practical anatomy. This study was conducted in institute of anatomy, madras medical college, Chennai, Tamilnadu, India. Age and sex of these adult cadavers were not determined.

\section{RESULTS}

The present study was conducted in 60 adult cadavers. Out of these sixty cadaveric specimens, Caterpillar hump (Moynihan hump) of right hepatic artery was present in two specimens in this study and making the incidence as $3.33 \%$. The right hepatic artery was coursing behind common hepatic duct before forming single loop of Caterpillar hump in these two specimens. Cystic artery was single in number and it is very short in both the specimens.

Fig. 1: First specimen of Caterpillar hump of right hepatic artery with short cystic artery.

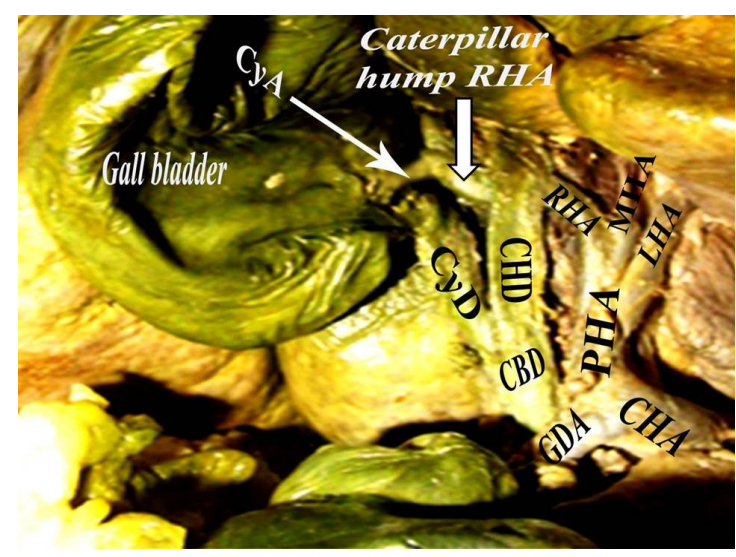


Fig. 2: Second specimen of Caterpillar hump of right hepatic artery with short cystic artery.

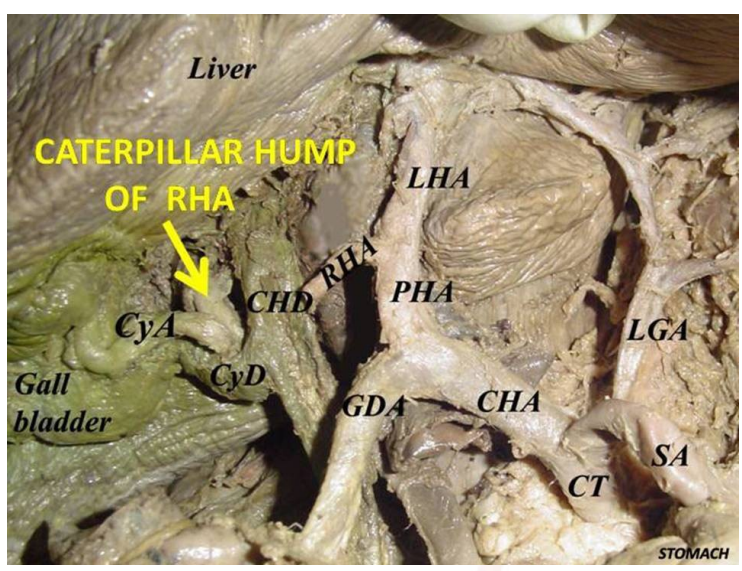

\section{DISCUSSION}

Incidence of caterpillar hump of right hepatic artery in the present study is $3.33 \%$. This variation was observed in $5-15 \%$ in Benson \& Page study [10], and in 5\% in Devi jansirani et al study [11]. It was present in $6-16 \%$ cases in Carol et al study [12]. Bergamaschi et al [13] found this variation as $12.9 \%$ in their postmortem study. But the incidence of caterpillar hump artery was low as $1.6 \%$ in Prithi LM et al study [14].

Dual cystic arteries in association with caterpillar hump of right hepatic artery was found in Kavitha kamath study [15]. But this type of variation is not seen in the present study.

I could not find more information about etiology of caterpillar hump of right hepatic artery. But finally I got some information from Taylor et al study [16]. They gave a possible explanation about the etiology of caterpillar hump formation, and according to them the hepatic artery is more liable to become elongated and tortuous during cirrhosis of liver, and they stated that it may be due to underlying architectural distortion associated with corkscrewing of intrahepatic branches of hepatic artery.

In Malik et al study [17], they found both single loop and double loop in caterpillar hump of right hepatic artery and the latter was common in their findings. But in my present study both the specimens are showing single loop only.

\section{CONCLUSION}

So When performing cholecystectomy, the surgeon must remember that there are many variations from the normal anatomy of the vessels and bileducts in Calots triangle. Because of these anatomical variations of cystic artery and right hepatic artery, surgical injuries in the living body can inadvertently and readily be made by even the most experienced surgeon So presence of caterpillar hump of right hepatic artery should be suspected when an unusually large cystic artery is viewed through the laparoscope and thus the surgeons can save the patient from the possibility of iatrogenic ischemic necrosis of right lobe of liver .

\section{ABBREVIATIONS}

CyD - Cystic duct

CHD - Common hepatic duct

CBD - Common bile duct

CT - Coeliac trunk

SA - Splenic artery

LGA - Left gastric artery

RGA - Right gastric artery

CHA - Common hepatic artery

PHA - Proper hepatic artery

GDA - Gastroduodenal artery

RHA - Right hepatic artery

LHA - Left hepatic artery

MHA - Middle hepatic artery

CyA - Cystic artery

\section{ACKNOWLEDGEMENTS}

The author is very grateful to Dr.N.Mugunthan, Associate Professor, Department of Anatomy, Mahatma Gandhi medical college, Pondicherry and Dr.Christilda Felicia, Professor, Department of Anatomy, SRM medical college, Chennai for their guidance and support to conduct this research work.

\section{Conflicts of Interests: None}

\section{REFERENCES}

[1]. Gray's anatomy for students, First edition, 2005:292-293.

[2]. Margaret Farquharson and Brendon Moran, textbook of operative general surgery, Ninth edition , 2005:321-331.

[3]. Lee McGregor, Surgical synopsis of surgical anatomy, 14 th edition, 1999:93-94 .

[4]. D. N. Dwivedi, Complications of Biliary tract surgery, volume 7 , 2000:132-135.

[5]. Keith L .Moore, Clinically oriented anatomy, $6^{\text {th }}$ edition , 2009;287-288. 
[6]. Flint.E.R. Abnormalities of the right hepatic, cystic and gastroduodenal arteries, and of the bile ducts , British journal of surgery, 1923;10:509519 .

[7]. Sanjai Nagral, CME article 2005;1(2):53-58 .

[8]. Bhargava G.S, Singh H, Singh H.D and Gupta R., Moynihan's hump of right hepatic artery - a case report and surgical significance. CIBTech Journal of Surgery 2014;3(2):42-44.

[9]. Crost DW, Gadacez TR. Laparoscopic anatomy of the biliary tree. Surg Clin North Am. 1993;73:785-798 .

[10]. Benson EA and Page RE. A practical reappraisal of the anatomy of the extrahepatic bile ducts and arteries. British Journal of Surgery. 1976;63:854.

[11].Devi Jansirani, N Mugunthan, V Phalgunan, S Shivadeep. Caterpillar hump of right hepatic artery : Incidence and surgical significance. National Journal of Clinical Anatomy. 2012;1(3):121-124.

[12]. Carol EH, Scott-Conner, David LD, (Ed). Operative Anatomy. $3^{\text {rd }}$ edn. Lippincott, Williams \& Wilkins. Philadelphia,2008:439.

[13]. Bergamaschi R, ignjatovic D, More than two structures in Calots triangle - A postmortem study. Surg.Endosc. 1999;14(4):354-357.
[14]. Prithi LM , Lakshmi R . Variant right hepatic artery from Moynihan's hump - clinical relevance. International Journal of Anatomic Variations .2010;3:144-155.

[15]. Kavitha kamath.B. Dual Cystic Arteries in Association with Caterpillar Hump of Right Hepatic Artery A Case Report and its Surgical Relevance. Journal of clinical \& diagnostic research. DOI: 10.7860/ JCDR/2015/13089.6156.

[16]. Taylor CR (20 November 2013). Cirrhosis imaging. Available: http:// www.emedicine. medscape .com/ article/ 366426 - overview, [ Accessed 31 December 2016 ].

[17]. Malik KA, Muneeb MD, Jawaid M, Muhammad LU and Zaman K. Post laparoscopic cholecystectomy hepatic artery pseudoaneurysm. Pakistan Journal of Surgery 2010;26(1):89-91.

How to cite this article:

K. Sangameswaran, M. Rohini devi. SURGICAL IMPORTANCE OF CATERPILLAR (MOYNIHAN) HUMP OF RIGHT HEPATIC ARTERY. Int J Anat Res 2017;5(2.1):3672-3675. DOI: 10.16965/ijar.2017.136 